\title{
PENERAPAN METODE FRAME BY FRAME DALAM PEMBUATAN ANIMASI TATA CARA HAJI SESUAI SUNNAH RASUL MENGGUNAKAN APLIKASI 3DS MAX
}

\author{
Aldina Syahfaridzah ${ }^{\bowtie}$, Khairunnisa, Dharmawati \\ Teknik Informatika, Universitas Harapan, Medan, Indonesia \\ Email: syahfaridzahaldina@gmail.com
}

DOI: https://doi.org/10.46880/jmika.Vol5No1.pp9-16

\begin{abstract}
Advances in technology in the field of information are developing very rapidly at this time, especially information in the field of animation. The animation is a visual form that moves and is used to present information and learning that is difficult to understand if delivered in general. The use of animation media is specially made to find out the procedures for the Hajj pilgrimage in order to increase knowledge for someone who wants to perform the Hajj or want to know the Hajj procedures because Hajj is the fifth pillar of Islam where if someone carries it out, much wisdom will be gained. Information about the pilgrimage procedures is packaged with $3 D$ animation and created using 3Ds Max application and the frame by frame method, where all movements of the animation are arranged using frames. So that the resulting learning media, namely animated videos that add insight and information for someone because it is packaged with media that is more attractive and easy to understand, namely animation.
\end{abstract}

Keyword: 3D Animation, Hajj, 3Ds Max, Frame by Frame.

\begin{abstract}
ABSTRAK
Kemajuan Teknologi dalam bidang informasi berkembang sangat pesat pada saat ini, terutama informasi dalam bidang animasi. Animasi merupakan salah satu bentuk visual yang bergerak dan dimanfaatkan untuk memberikan informasi dan pembelajaran yang sulit dimengerti jika disampaikan secara umum. Penggunaan media animasi dibuat khususnya untuk mengetahui tata cara ibadah haji agar dapat menambah pengetahuan bagi seseorang yang ingin melaksanakan ibadah haji atau sekedar ingin mengetahui tata cara ibadah haji tersebut, karena haji merupakan rukun islam yang kelima dimana jika seseorang melaksanakannya maka banyak hikmah yang akan di dapat. Informasi mengenai tata cara haji ini dikemas dengan animasi 3D serta dibuat menggunakan aplikasi 3Ds Max dan metode Frame by Frame, dimana seluruh gerakan dari animasi diatur menggunakan frame. Sehingga, dihasilkan media pembelajaran yaitu video animasi yang menambah wawasan serta informasi bagi seseorang karena dikemas dengan media yang lebih menarik dan mudah dipahami yaitu animasi.
\end{abstract}

Kata Kunci: Animasi 3D, Haji, 3Ds Max, Frame by Frame.

\section{PENDAHULUAN}

Setiap tahun, angka Umat Islam Indonesia yang menunaikan Ibadah Haji ke Tanah Suci Mekkah terus menerus meningkat. Ibadah Haji merupakan Rukun Islam yang ke lima setelah Syahadat, Sholat, Zakat, dan Puasa. Terdapat amalan atau tata cara yang harus dilakukan seseorang dalam melaksanakan Ibadah Haji seperti Ihram, Thawaf, Sai, Wukuf di Arafah, Mabit di Muzdalifah, Melontar Jamrah, bercukur atau gundul atau memotong beberapa helai rambut. (Halik, 2019)

Pada zaman sekarang ini banyak media informasi yang dibuat semenarik mungkin untuk membuat seseorang tertarik melihat dan mengetahuinya seperti halnya animasi. Animasi memiliki keunggulan tersendiri sebagai media informasi dibanding dengan media lainnya seperti gambar statis dan teks, karena animasi dibuat dengan gambar yang bergerak sehingga informasi yang disampaikan lebih mudah untuk dipahami. (Aziz, 2019)

Banyak aplikasi yang mendukung dalam pembuatan animasi 3D seperti aplikasi 3DS Max, dengan menggunakan aplikasi 3DS Max para perancang produk dapat memodelkan objek dalam bentuk 3D ataupun 2D. Aplikasi ini merupakan salah satu aplikasi yang sering digunakan oleh para perancang dikarenakan aplikasi ini cukup memudahkan pengguna untuk menggali kemampuan dan daya imajinasi perancang dalam menghasilkan suatu hasil karya baik objek ataupun karakter. (Suhendar \& Fernando, 2016) 
Dalam pembuatan animasi terdapat beberapa jenis metode yang digunakan dalam proses perancangan animasi yang akan dibuat, metode Frame by Frame sebagai salah satunya. Dimana metode frame by frame dilakukan dengan cara bertahap yaitu objek yang akan digerakan diatur satu persatu secara manual mengikuti sebuah frame yang telah ditentukan. (Firmansyah \& Kurniawan, 2013)

Dalam pembuatan animasi banyak aplikasi editing video yang dapat membantu membuat animasi semakin menarik seperti penambahan teks, perubahan atau transisi setiap frame dan juga pengisi suara. Aplikasi Filmora adalah salah satunya, aplikasi ini merupakan aplikasi yang sering dianjurkan untuk para editor video pemula karena selain programnya yang ringan jika dibandingkan dengan aplikasi editing video yang lain, aplikasi ini juga dirancang dengan tampilan kerja yang sangat sederhana dan mudah untuk dipelajari. (Nida, 2019)

Berdasarkan paragraf sebelumnya terdapat permasalahan yang akan dibahas yaitu, Bagaimana menyajikan informasi yang lebih menarik menggunakan media animasi? Bagaimana memanfaatkan aplikasi 3DS Max dalam pembuatan animasi mengenai tata cara haji? Bagaimana menerapkan metode frame by frame dalam pembuatan animasi mengenai tata cara haji menggunakan aplikasi 3DS Max?.

Penelitian ini bertujuan untuk membuat informasi yang lebih menarik menggunakan media animasi, mengimplementasikan aplikasi 3DS Max dalam pembuatan animasi mengenai tata cara haji, dan mengimplementasikan Metode Frame by Frame pada karakter dalam pembuatan animasi tata cara haji menggunakan aplikasi 3DS Max. Dan memiliki manfaat Membantu seseorang memperoleh informasi mengenai tata cara haji yang dikemas dengan media animasi sehingga mudah dipahami, Menambah wawasan seseorang mengenai animasi yang dapat menjadi media informasi yang lebih menarik.

Penelitian ini dibuat dari penelitian sebelumnya, dimana peneliti tersebut membahas pengetahuan mengenai tata cara menjalankan ibadah umroh yang dianimasikan menggunakan aplikasi Blender 3D dan peneliti mengembangkannya dengan membahas mengenai tata cara ibadah haji tetapi menggunakan aplikasi yang berbeda yaitu, aplikasi 3DS Max.

\section{TINJAUAN PUSTAKA}

Haji

Menunaikan ibadah haji merupakan rukun islam kelima setelah syahadat, shalat, zakat, dan puasa.
Seorang muslim yang telah mampu memenuhi persyaratan baik secara fisik, biaya dan waktu wajib untuk melaksanakan ibadah ini. Ibadah haji memiliki arti khusus tersendiri dibandingkan dengan ibadah yang lain seperti sholat, puasa, membayar zakat, membaca Al- Quran serta lainnya karena tidak dilakukan disembarang tempat dan waktu, ibadah haji ini harus dilakukan di Tanah Suci Mekah al-Mukarramah dan pada bulan haji atau Zulhijah. Haji menurut bahasa adalah mengunjungi sesuatu, sedangkan menurut islam adalah mengunjungi Ka'bah yaitu dengan tujuan beribadah kepada Allah Swt. Haji dapat dilakukan mulai tanggal 8 Zulhijah dan berakhir pada tanggal 12 atau 13 Zulhijah. Dalam melaksanakan ibadah haji terdapat aturan atau tata cara yang dapat menentun seorang muslim yang ingin melaksanakan ibadah haji, adapun tata cara dalam melakukan ibadah haji adalah : Ihram, Wukuf di Arafah, Mabit di Muzdalifah dan mengumpulkan krikil, Melempar Jumrah, Tahallul, Mabit di Mina, Melakukan Tawaf Ifadhah, Sholat di belakang Maqam Ibrahim dan Hijir Ismail, Berdoa di Multazam, Melakukan Sa'i antara bukit Shafa dan MarwahMelakukan Tawaf Wada. (Halik, 2019)

\section{Animasi}

Animasi adalah salah satu bentuk visual yang menggabungkan grafik atau teks menjadi sebuah aktivitas gerakan yang dimanfaatkan untuk memberikan informasi dan pembelajaran yang sulit dimengerti jika disampaikan secara umum. Kata animasi berasal dari Bahasa latin, anima yang berarti hidup dan kemudian Bahasa itu dirangkum kedalam bahasa Inggris yaitu animate atau animation yang berarti hidup atau memberikan ilusi dari sebuah gerakan. Selanjutnya kata animation dirangkum kedalam bahasa Indonesia menjadi kata animasi. Dimana dalam kamus besar bahasa Indonesia, kata animasi didefiniskan menjadi acara televisi yang berbentuk rangkaian lukisan atau gambar yang digerakkan secara mekanik elektronis sehingga tampak dilayar menjadi bergerak. (Aziz, 2019)

\section{Metode Animasi Frame by Frame}

Dalam pembuatan animasi terdapat beberapa jenis metode yang digunakan dalam proses perancangan animasi yang akan dibuat, metode Frame by Frame sebagai salah satunya. Dimana metode frame by frame dilakukan dengan cara bertahap yaitu objek yang akan digerakan diatur satu persatu secara manual mengikuti sebuah frame yang telah ditentukan sehingga menghasilkan perubahan gambar yang teratur dan semakin banyak frame yang digunakan untuk 
menampung setiap detail gerakan dari sebuah karakter atau objek maka semakin halus dan bagus animasi yang dihasilkan. Metode Frame by Frame merupakan teknik animasi yang disusun dari banyak rangkaian gerakan yang berbeda. Pada metode ini, setiap perubahan gerakan sebuah objek diatur sesuai kebutuhan dan diletakkan pada frame yang telah ditentukan secara berurutan. (Firmansyah \& Kurniawan, 2013)

\section{Aplikasi 3DS Max}

Banyak aplikasi yang mendukung dalam pembuatan animasi 3D seperti aplikasi 3DS Max, dengan menggunakan aplikasi 3DS Max para perancang produk dapat memodelkan objek dalam bentuk 3D ataupun 2D. Dalam 3DS Max terdapat tiga bentuk dasar dari animasi sederhana, yaitu animasi menggerakkan atau memindahkan objek dari satu posisi ke posisi lain sesuai sumbu koordinat, animasi memutar objek dan animasi mengatur skala objek dengan menghubungkan path. Aplikasi ini merupakan salah satu aplikasi yang sering digunakan oleh para perancang dikarenakan aplikasi ini cukup memudahkan pengguna untuk menggali kemampuan dan daya imajinasi perancang dalam menghasilkan suatu hasil karya baik objek ataupun karakter. (Suhendar \& Fernando, 2016)

\section{Aplikasi Filmora}

Filmora atau lengkapnya adalah Wondershare Filmora Video Editor merupakan aplikasi editing video yang dirancang untuk membuat proses dalam pengeditan video terlakukan dengan lebih mudah, tetapi tetap memiliki kualitas yang cukup tinggi. aplikasi filmora ini juga sering dianjurkan untuk para pemula editor video karena lebih mudah digunakan. Sifatnya yang ringan membuat aplikasi filmora mampu dijalankan pada perangkat yang memiliki spesifikasi rendah. (Lestari et al., 2019)

\section{Storyboard}

Storyboard merupakan naskah yang dituangkan dalam bentuk gambar atau sketsa yang berguna untuk lebih memudahkan cameraman dalam pengambilan gambar. Storyboard adalah area berseri dari sebuah gambar sketsa yang digunakan sebagai alat perencanaan untuk menunjukkan secara visual bagaimana aksi dari sebuah cerita berlangsung. (Nurhasanah \& Senyelda, 2016)

\section{METODE PENELITIAN}

Teknik pengumpulan data pada penelitian ini adalah sebagai berikut:

1. Studi Literatur

Pada tahapan ini, studi literatur dilakukan dengan pengumpulan bahan pustaka atau referensi mengenai tata cara dalam melaksanakan haji, animasi 3D, editing video dan metode frame by frame yang bersumber dari buku-buku dan jurnaljurnal dari penelitian yang sudah ada sebelumnya.

2. Analisis Perancangan dan Implementasi

Pada tahapan ini, dilakukan perancangan story board, dubbing, mengimplementasikan metode frame by frame dalam pembuatan gerakan pada karakter yang menjelaskan tata cara haji dan akan terbentuk menjadi animasi.

3. Pengujian dan analisis hasil

Pada tahapan ini, pengujian terhadap hasil video animasi 3D mengenai tata cara haji apakah dapat menyampaikan pembahasan penelitian dengan mudah dipahami dan analisis hasil untuk memeriksa apakah hasil dari penelitian sudah sesuai dengan masalah yang diteliti.

4. Penyusunan Laporan

Pada tahapan ini, akan dilakukan penyusunan laporan dari hasil penelitian yang telah dilakukan menjadi suatu kesimpulan agar didapatkan cara penyelesaian masalah yang lebih jelas.

\section{Kerangka Kerja Animasi}

Setelah membuat kerangka kerja atau gambaran serta langkah-langkah sebelum membuat animasi seperti dibawah ini :

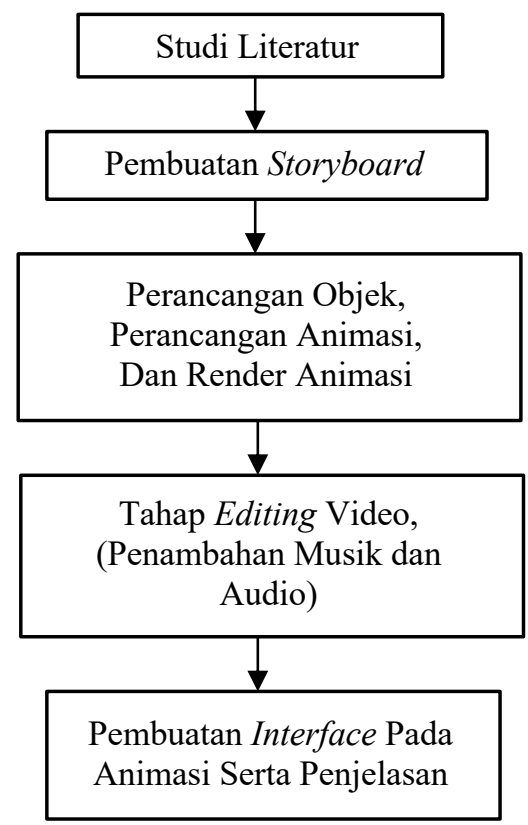

Gambar 1. Kerangka Kerja Animasi 


\section{Tahap Pra Produksi}

Pra produksi merupakan perancangan, perencanaan serta pembuatan sketsa dari beberapa elemen yang terpisah menjadi satu kesatuan yang utuh dan juga berfungsi. Pada tahap pra produksi ini membuat storyboard sebagai alur cerita dari video animasi yang akan dibuat, seperti dibawah ini :

Tabel 1. Storyboard Animasi Tata Cara Haji

\begin{tabular}{|c|c|c|c|}
\hline $\begin{array}{c}\text { Sce } \\
\text { ne }\end{array}$ & Board & Naskah & Durasi \\
\hline 1 & & Ihram & $\begin{array}{c}109 \\
\text { Detik }\end{array}$ \\
\hline 2 & & $\begin{array}{c}\text { Wukuf } \\
\text { di } \\
\text { Arafah }\end{array}$ & $\begin{array}{c}21 \\
\text { Detik }\end{array}$ \\
\hline 3 & & $\begin{array}{l}\text { Mabit } \\
\text { di } \\
\text { Muzdal } \\
\text { ifah }\end{array}$ & $\begin{array}{c}19 \\
\text { Detik }\end{array}$ \\
\hline 4 & & $\begin{array}{l}\text { Melem } \\
\text { par } 3 \\
\text { Jumrah }\end{array}$ & $\begin{array}{c}74 \\
\text { Detik }\end{array}$ \\
\hline 5 & & $\begin{array}{l}\text { Tahallu } \\
\text { 1 Awal }\end{array}$ & $\begin{array}{c}19 \\
\text { Detik }\end{array}$ \\
\hline 6 & & $\begin{array}{c}\text { Mabit } \\
\text { di Mina }\end{array}$ & $\begin{array}{c}18 \\
\text { Detik }\end{array}$ \\
\hline 7 & & $\begin{array}{l}\text { Tawaf } \\
\text { Ifhadah }\end{array}$ & $\begin{array}{c}82 \\
\text { Detik }\end{array}$ \\
\hline
\end{tabular}

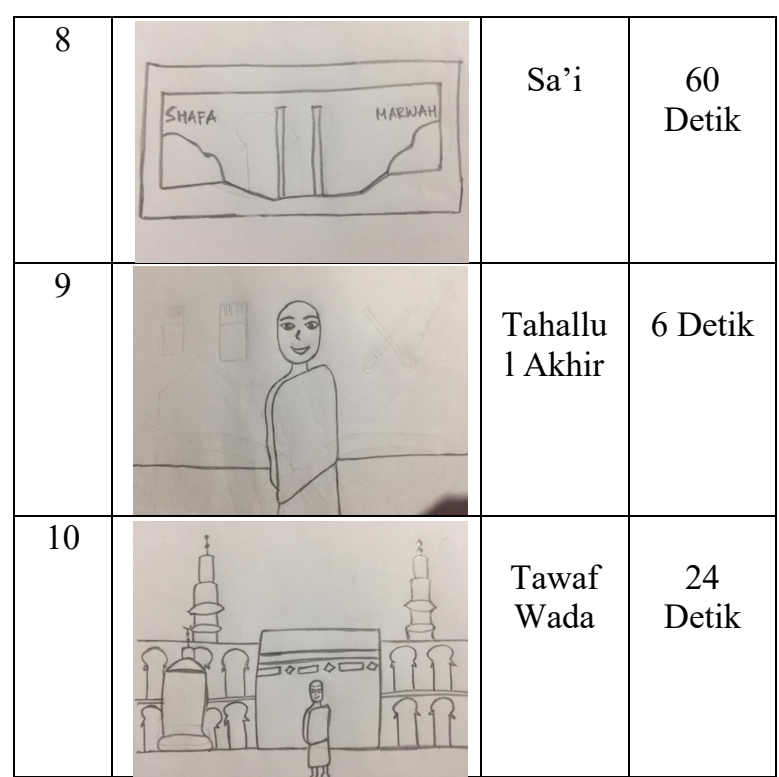

Tahap Produksi

Produksi merupakan tahapan dimana pembuatan atau perancangan dari animasi tersebut dimulai. Pada tahap produksi terdapat beberapa tahapan yaitu, perancangan objek dan perancangan animasi.

\section{Perancangan Objek}

Tahapan ini merupakan tahapan dari proses perancangan atau pembuatan objek-objek yang akan ditampilkan pada video animasi. Adapun beberapa objeknya sebagai berikut :

\section{Perancangan Karakter 3D}

Dalam perancangan karakter 3D pertama menggunakan objek plane yang akan diletakkan contoh gambar karakter manusia sebagai panduan dalam membuatnya. Kedua, ambil objek box dan letakkan di depan plane sebelumnya dengan mengurangkan opacity agar dapat melihat gambar dibelakang box. Atur box dengan scala dan dibantu dengan menggunakan tools editable poly pada 3DS Max. Sehingga box dapat membentuk badan, kaki, dan tangan. Dan pada bagian muka dan jari diambil dari karakter yang sudah ada pada halaman web TurboSquid yaitu www.turbosquid.com. Berilah warna pada karakter sesuai yang di butuhkan. 


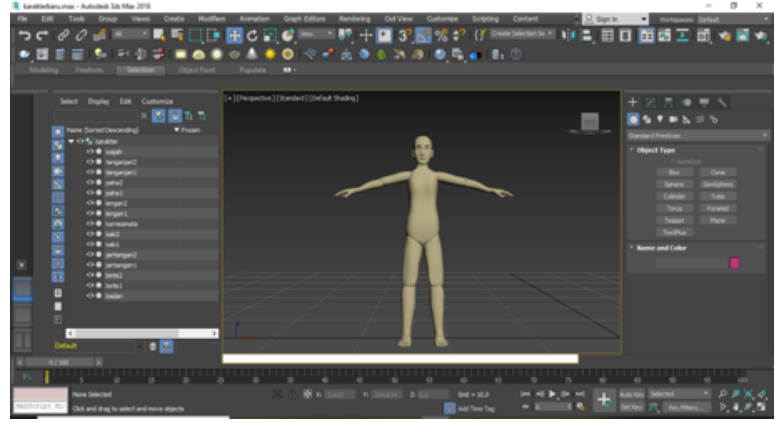

Gambar 2. Hasil Perancangan Karakter 3D

\section{Perancangan Baju Ihram Karakter 3D}

Dalam pembuatan Pakaian pada karakter utama 3D menggunakan sisi 2D, pertama gambar baju menggunakan tools line dan copy sehingga menjadi dua. Kedua, attach celana yang sudah digambar dan pada break pada vertex line. Ketiga, pada modifier list klik garment maker, selanjutnya pilih panels dan atur posisi gambar celana menjadi depan belakang dari karakter. Keempat, pilih seams pada garment maker selanjutnya klik create seam dan pilih garis-garis yang akan disatukan. Kelima, pada modifier list klik cloth selanjutnya klik object properties lalu klik add object dan pilih bagian pada karakter mana yang akan diletakkan pakaian. Pada line klik cloth dan pada presets klik rubber lalu klik ok. Terakhir pada simulation klik simulate local untuk menyatukan garisgaris pada pakaian. Dan terakhir dalam pembuatan rambut pada kepala karakter di editable poly, selanjutnya polygon dan extrude.

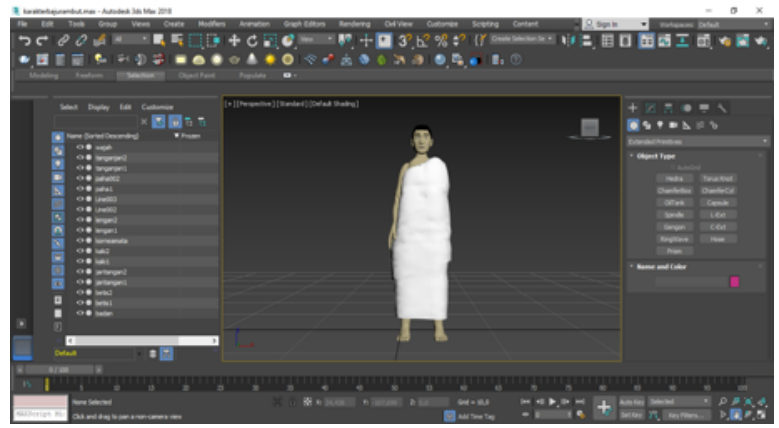

Gambar 3. Hasil Perancangan Baju Ihram Karakter 3D

\section{Perancangan Ka'bah 3D}

Dalam perancangan ka'bah 3D, pertama ambil objek box dan klik editable poly. Selanjutnya klik edge, pilih garis untuk menambah garis baru dan klik connect. Atur angka pada connect untuk ukiran pada Ka'bah. Lakukan lagi pada untuk ukiran lainnya pada cara yang sama, dan beri warna disetiap ukirannya. Untuk Hajar Aswad dibuat dengan menggunakan objek torus. Dan selanjutnya, satukan Ka'bah yang sudah dirancang sebelumnya dengan Hajar Aswad menggunakan move.

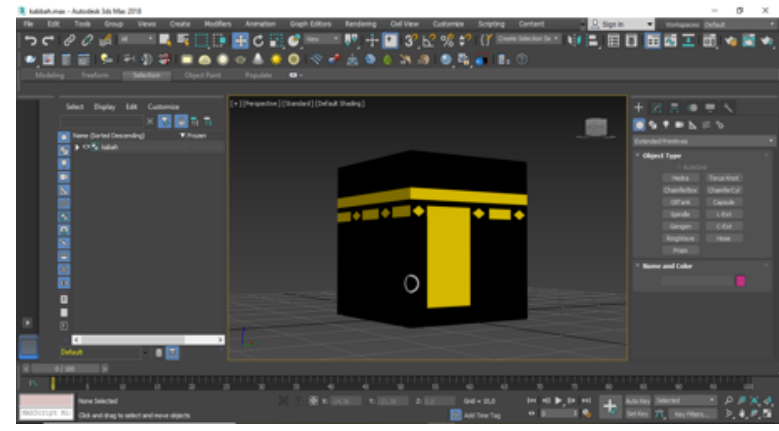

Gambar 4. Hasil Perancangan Ka'bah 3D

\section{Perancangan Animasi}

Tahapan perancangan animasi ini dimulai setelah tahapan perancangan objek telah selesai, dimana pada tahapan ini objek yang telah dirancang terlebih dahulu diatur gerakannya sesuai alur cerita atau storyboard dan setiap perubahan gerakan akan ditandai dengan setiap frame yang akan diatur sendiri sesuai kebutuhan dan konsep, seperti yang dimaksud adalah metode frame by frame.

\section{Pembuatan Animasi Tawaf Ifadhah}

Animasi tawaf ifadhah membutuhkan 300 frame. Animasi saat tawaf dibuat dengan kamera dan gerakan pada animasi selebihnya diatur menggunakan frame. Dan gerakan pertama pembuka membutuhkan 40 frame. Geser angka frame ke 20 dan munculkan teks menggunakan scala. Selanjutnya geser kembali angka frame ke 40 dan hilangkan teks dengan scala.

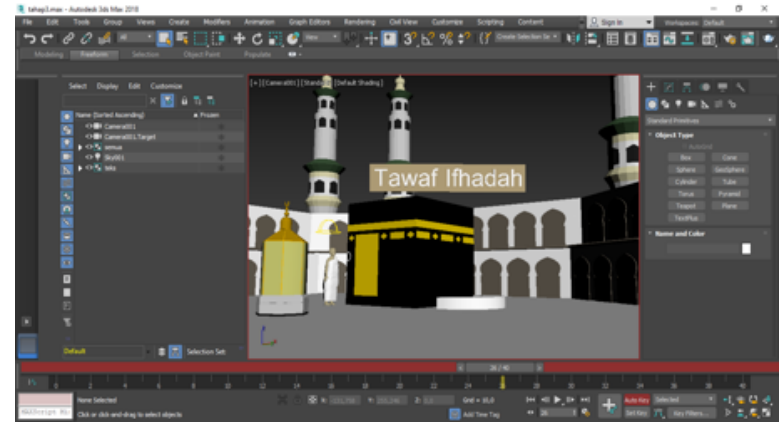

Gambar 5. Tampilan Pembuatan Animasi Tawaf Ifadhah Frame 0 sampai 40

Dan untuk mengelilingi Ka'bah membutuhkan 1060 frame, gerakan pada karakter di lakukan setiap 10 frame dimana kaki pada karakter diatur satu per satu ke depan dan ke belakang. Dan kamera bergerak mengikuti arah karakter berjalan. 


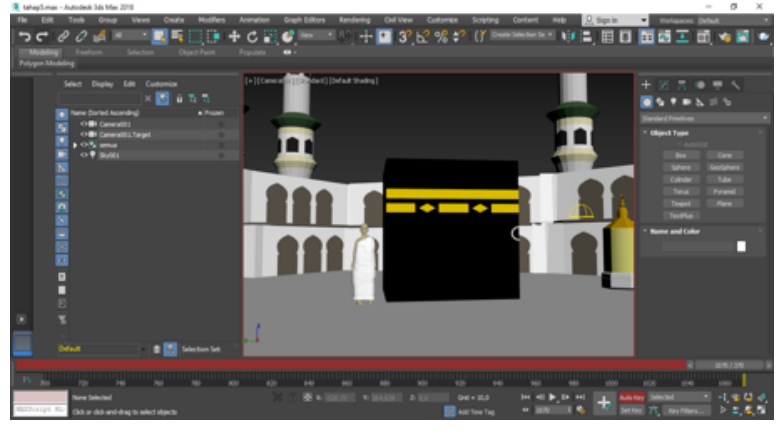

Gambar 6. Tampilan Pembuatan Animasi Tawaf Ifadhah Frame 40 sampai 1060

\section{Tahap Pasca}

Tahapan pasca merupakan tahapan terakhir dalam pembuatan animasi ini, dimana pada tahapan ini dilakukan setelah tahapan produksi selesai dirancang atau dibuat. Pada tahap pasca terdapat beberapa tahapan seperti rendering dan editing.

\section{Rendering}

Rendering merupakan tahapan akhir dalam proses pembuatan animasi, dimana pada tahapan ini menjadi tahapan yang akan menampilkan hasil dari animasi yang telah dibuat sebelumnya secara utuh menggunakan aplikasi animasi 3d. pada tahapan ini, dapat dilihat hasil dari gerakan objek atau karakter yang telah diatur sesuai frame nya. Adapun cara rendering animasi yang telah dirancang dengan menggunakan pencahyaan skylight antara lain, sebagai berikut :

Pertama Klik menu lights, ubah pilihan menjadi standard, selanjutnya klik skylight pada object type dan terakhir klik sekali dilembar kerja untuk memberi pencahayaan skylight pada animasi yang telah dirancang.

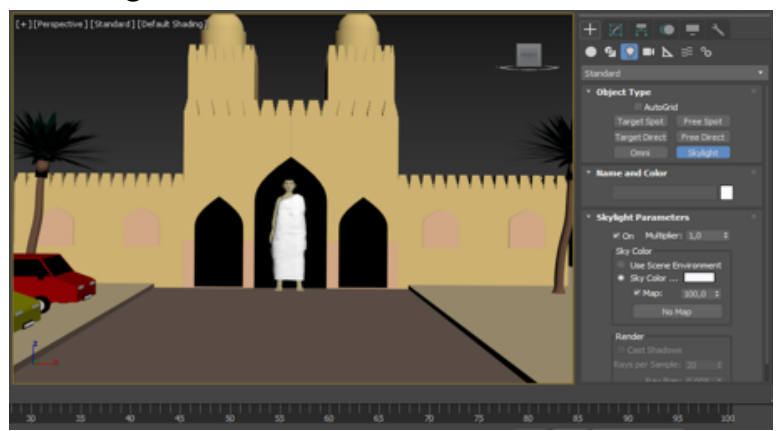

Gambar 7. Langkah Pertama Untuk Rendering

Kedua Klik menu rendering, klik environment dan pilih warna untuk background pada menu color dari animasi yang telah dirancang.

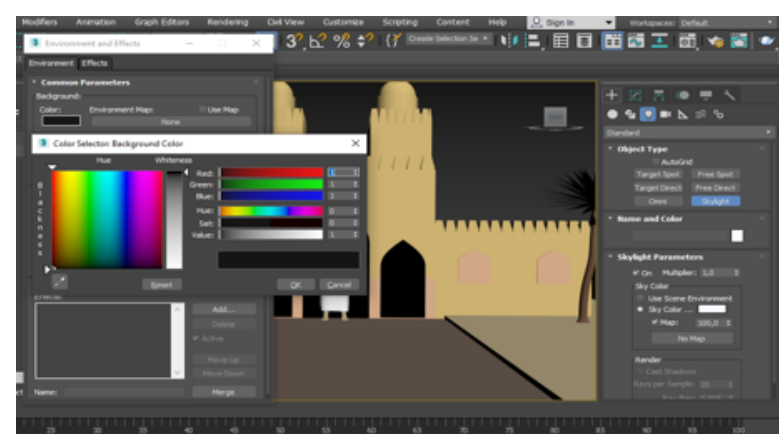

Gambar 8. Langkah Kedua Untuk Rendering

Ketiga Klik kembali menu rendering, klik light tracer, ubah single menjadi Active Time Segment.

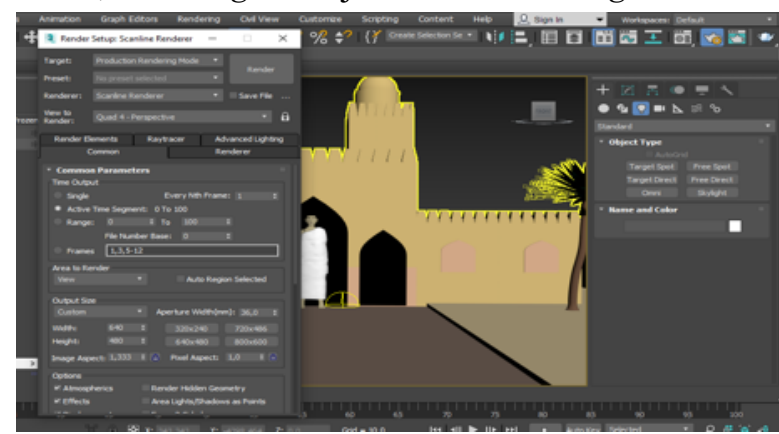

Gambar 9. Langkah Ketiga Untuk Rendering

Keempat Pilih tempat penyimpanan untuk animasi yang telah dirancang pada Render Output.

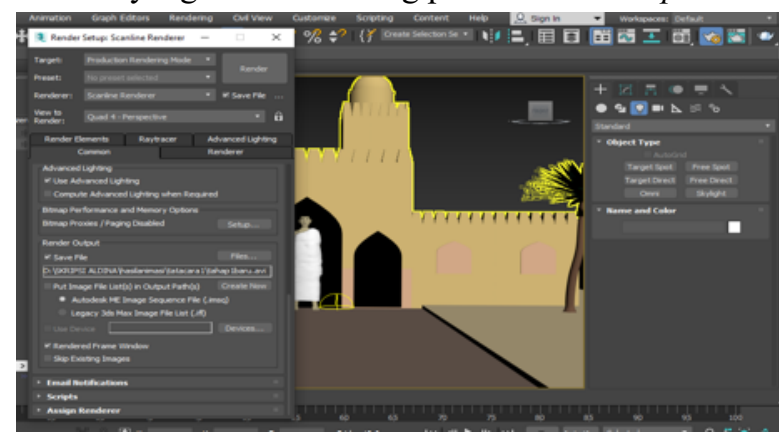

Gambar 10. Pilih Tempat Penyimpanan

Selanjutnya Langkah terakhir klik Render dan tunggu sampai proses render berhenti.

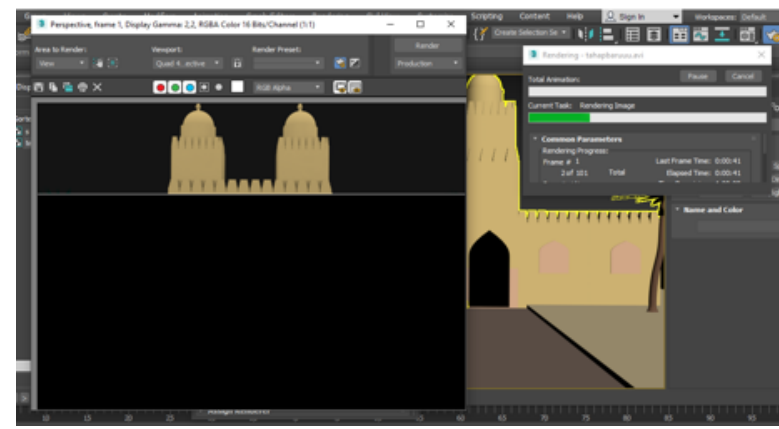

Gambar 11. Proses Hasil Dari Rendering 


\section{Editing}

Editing merupakan tahapan yang dapat sangat membantu memaksimalkan hasil dari video animasi yang dibuat pada penelitian ini, proses ini membantu memberikan berupa teks, efek, tansisi, memberikan suara atau dubbing serta pengaturan durasi cepat dan lambatnya video animasi yang akan ditampilkan.

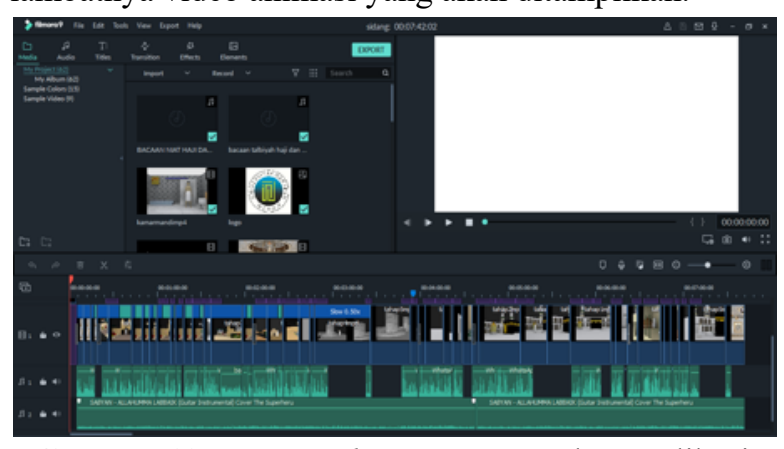

Gambar 12. Proses Editing menggunakan Aplikasi Filmora.

\section{HASIL DAN PEMBAHASAN}

Dihasilkan sebuah media pembelajaran yaitu video animasi yang menjelaskan apa saja tata cara haji yang wajib dilakukan sesuai dengan rukunnya dan menjadi alternatif yang lebih menarik serta mudah dipahami dalam menambah wawasan dan informasi bagi seseorang yang ingin melaksanakan ibadah haji atau yang sekedar ingin mengetahuinya. Animasi ini dapat dilihat dengan menggunakan smartphone ataupun laptop.

Beberapa tampilan hasil animasi yang telah dirancang, adalah sebagai berikut:

Tampilan Melempar Jumrah, dengan meletakkan karakter disamping tempat pelemparan Jumrah dan karakter memegang krikil yang akan dilemparkan. Didalam video animasi, karakter bergerak melempari ketiga Jumrah.

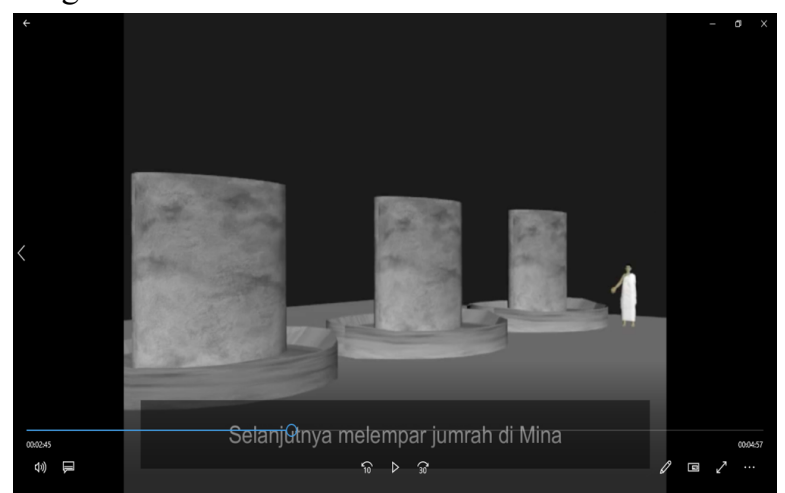

Gambar 13. Tampilan Melempar Jumrah

Tampilan Melakukan Thawaf, dengan meletakkan karakter disamping Ka'bah. Didalam video animasi, karakter berjalan mengelilingi ka'bah.

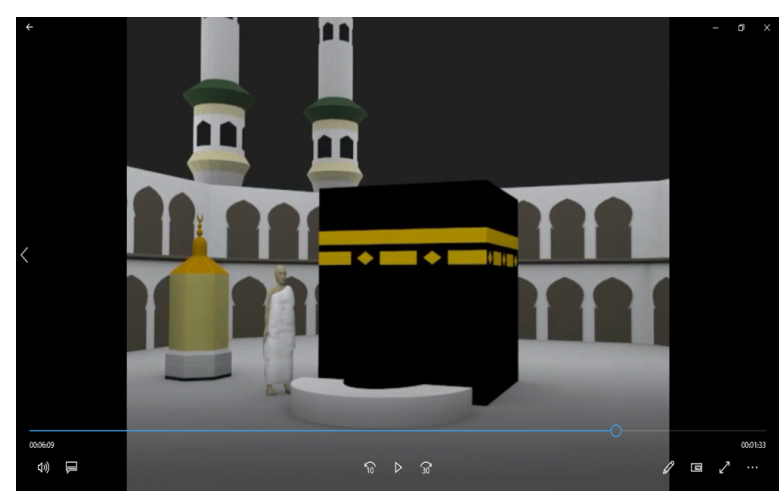

Gambar 14. Tampilan Melakukan Thawaf

Penelitian ini dapat dikembangkan dengan menggunakan aplikasi 3D lain seperti Blender dan menggunakan metode animasi lain, sebagai pembuatan animasinya.

\section{KESIMPULAN}

Berdasarkan hasil perancangan yang telah dijelaskan mengenai tata cara haji, dapat ditarik kesimpulan bahwa penyajian informasi menggunakan animasi dapat menjadi lebih menarik karena ditampilkan secara 3D (tiga dimensi), Aplikasi 3DS Max cukup mudah untuk dipelajari karena terdapat banyak referensi yang tersedia. Tools dan objek-objek pada 3DS Max dapat memudahkan dalam pembuatan animasi dan Penerapan metode frame by frame dalam pembuatan animasi yaitu dengan mengatur gerakan animasi satu persatu menggunakan frame.

\section{DAFTAR PUSTAKA}

Aziz, Z. (2019). Fluxus Animasi Dan Komunikasi di Era Media Baru Digital. Channel Jurnal Komunikasi, 7(1), 49-58.

Firmansyah, A., \& Kurniawan, M. P. (2013). Pembuatan Film Animasi 2D Menggunakan Metode Frame By “Kancil Dan Siput.” Jurnal Ilmiah DASI, 14(04), 10-13.

Halik Lubis, H. (2019). Tuntunan Lengkap Wajib dan Sunnah Haji \& Umrah Penyusun. In Mulia.

Lestari, W. A., Tulloh, R., \& Novianti, A. (2019). Media Pembelajaran Interaktif Enkripsi Caesar Cipher, Vigenere Cipher, Dan Algoritma RSA. Jurnal E-Proceeding of Applied Science, 5(3), 2912-2924.

Nida, H. H. (2019). Penerapan Model Poe2we Dalam Pembuatan Video Pembelajaran Fisika Dengan Bantuan Aplikasi Filmora Sebagai Upaya Peningkatan Kemampuan Kognitif Dan Psikomotor Siswa. Journal of Chemical Information and Modeling, 53(9), 1689-1699. https://doi.org/10.1017/CBO9781107415324.00 4 
Nurhasanah, Y. I., \& Senyelda, D. (2016).

Implementasi Model CMIFED Pada Multimedia

Interaktif Untuk Pembelajaran Anak Usia TK

Dan Playgroup. Jurnal Informatika, Vol. 2(2),

12.

Suhendar, A., \& Fernando, A. (2016). Aplikasi Virtual

tour Berbasis Multimedia Interaktif

Menggunakan Autodesk 3Ds Max. Jurnal

ProTekInfo, 3(1), 30-35. 